\title{
Detection of Antimicrobial Resistance in Escherichia coli and Salmonella Isolated from Flies Trapped at Animal and Poultry Farm Premises
}

\author{
Bhavna Wadaskar ${ }^{1}$, Rahul Kolhe ${ }^{1 *}$, Vikas Waskar ${ }^{1}$, Mrunalini Budhe $^{2}$, \\ Krishnendu Kundu ${ }^{3}$ and Sandeep Chaudhari ${ }^{4}$ \\ ${ }^{1}$ Department of Veterinary Public Health, KNP College of Veterinary Science, Shirwal, District Satara, \\ Maharashtra Animal \& Fishery Sciences University, Nagpur, INDIA \\ ${ }^{2}$ Department of Veterinary Microbiology, KNP College of Veterinary Science, Shirwal, District Satara, Maharashtra Animal \\ $\mathcal{E}$ Fishery Sciences University, Nagpur, INDIA \\ ${ }^{3}$ Department of Veterinary Parasitology, KNP College of Veterinary Science, Shirwal, District Satara, Maharashtra Animal \\ $\mathcal{E}$ Fishery Sciences University, Nagpur, INDIA \\ ${ }^{4}$ Department of Veterinary Public Health, Nagpur Veterinary College, Seminary Hills Nagpur, Maharashtra Animal E \\ Fishery Sciences University, Nagpur, INDIA \\ "Corresponding author: RP Kolhe; E-mail: dr_kolherahul@rediffmail.com
}

Received: 6 May, 2021

Revised: 26 May, 2021

Accepted: 29 may, 2021

\begin{abstract}
The aim of this study was to explore antimicrobial resistance in Escherichia coli and Salmonella species from flies trapped at livestock and poultry farm premises. A total of 36 pools of flies and 72 rectal/cloacae swabs were collected. All the flies were Musca domestica except one fly was Calliphora erythrocephala. E. coli were recovered from all the flies (100\%) and fecal $(100 \%)$ samples. Whereas, Salmonellae were obtained from $21(58.33 \%)$ flies and $15(20.83 \%)$ fecal samples. E. coli and Salmonella isolates were multi-drug resistant strains. E. coli exhibited resistance to amoxicillin-clavulanic acid (100\%), cefotaxime $(93.57 \%)$, aztreonam $(59.63 \%)$, cefpodoxime $(58.71 \%)$ and imipenem $(48.62 \%)$. Salmonellae were also $100 \%$ resistant to ampicillin-clavulanic acid followed by cefotaxime (91.66\%), cefpodoxime (94.44\%) and imipenem $(91.66 \%)$. Colistin resistance was recorded more in Salmonella (61.11\%) than E. coli $(12.84 \%)$ by phenotypic assays, however, $m c r 1$ to $m c r 5$ genes could not be detected in any of the E. coli and Salmonella isolates. Bacteria studied were ESBL (21.10\%) and MBL positive. Present study is suggestive of the fact that flies harbor multidrug resistant, ESBL, MBL and colistin resistant $E$. coli and Salmonella strains. Extensive monitoring of indicators organisms of AMR in unconventional reservoirs like flies is needed.
\end{abstract}

\section{HIGHLIGHTS}

(O Study focused on the detection of AMR in E. coli and Salmonella present in the flies.

( Musca domestica is highly prevalent at livestock and poultry farm premises.

(0 Flies harbor multidrug resistant, ESBL, MBL and colistin resistant E. coli and Salmonella strains in their gut.

Keywords: E. coli, Salmonella, AMR, flies, food animals, poultry

Antimicrobial resistance (AMR) is emerged as a global problem and today's situation is grave in the context of antimicrobial usage, AMR, and alternatives to the antimicrobial agents (Marshall and Levy, 2011). World Health Organization (WHO) published a list of priority bacterial pathogens belonging to 12 genera in 2017 and classified them as critical, high and medium priority, most of which are zoonotic bacterial pathogens. Enterobacteriaceae, carbapenem-resistant, ESBL producing organisms are grouped under critical priority.

How to cite this article: Wadaskar, B., Kolhe, R., Waskar, V., Budhe, M. Kundu, K. and Chaudhari, S. (2021). Detection of antimicrobial resistance in Escherichia coli and Salmonella isolated from flies trapped at animal and poultry farm premises. J. Anim. Res., 11(3): 341-350. Source of Support: None; Conflict of Interest: None 
Colistin is now considered as very critical antibiotic for human treatment against Gram negative organisms. Colistin as animal growth promoter (AGP) was practiced extensively at global scale which is responsible for the emergence of mobile colistin resistance $(\mathrm{mcr})$ genes. Emergence of colistin resistance in human and animal origin bacteria of Enterobacteriaceae family has been recently reported (Clemente et al., 2019). MCR genes are located on the transferable plasmid and till date, $\mathrm{mcr}$ - 1 to $m c r-10$ genes are detected in bacterial species, principally E. coli, Salmonella and Klebsiella pneumoniae (Wang et al., 2020). Colistin resistance is detected in bacteria associated with various sources viz. human, animals, food and invertebrates like flies (Zhang et al., 2017; Principe et al., 2018).

Studies on detection of colistin resistant in E. coli and Salmonella species are scanty from India except few recent studies on the K. pneumoniae (Singh et al., 2018). In view of the increasing AMR situation, it becomes mandatory to investigate the environmental resistomes of AMR. Mechanism of AMR in the bacterial population is a complex but natural and therefore, timely information on the prevalence and molecular epidemiology of critical antibiotics like colistin is required. Recent study on the microbiota of the blowflies and house flies has gained importance in terms of microbial dispersion and AMR (Junqueira et al., 2017). Houseflies can act as vector for harboring and spread of human enteric pathogens. They can even bio-enhance the transmission of AMR (Onwugamba et al., 2018). In the present investigation, attempts have been made to explore the role of flies in harboring antimicrobial resistant E. coli and Salmonella strains with special reference to colistin.

Table 1: Details of sample collection (flies and fecal samples)

\begin{tabular}{|c|c|c|c|c|c|c|c|c|c|}
\hline \multirow{2}{*}{$\frac{\text { Sl. No. }}{1}$} & \multirow{2}{*}{$\begin{array}{l}\text { Site } \\
\text { Cattle farm }\end{array}$} & \multicolumn{2}{|c|}{ No. of trappings } & \multicolumn{5}{|c|}{ Actual flies trapped per sampling } & \multirow{2}{*}{$\begin{array}{l}\text { Total flies } \\
234\end{array}$} \\
\hline & & 6 & 31 & 25 & 18 & 40 & 71 & 49 & \\
\hline 2 & Sheep farm & 6 & 47 & 39 & 44 & 53 & 50 & 48 & 281 \\
\hline 3 & Goat farm & 6 & 75 & 72 & 73 & 85 & 87 & 98 & 490 \\
\hline 4 & Pig farm & 6 & 40 & 30 & 112 & 62 & 75 & 91 & 410 \\
\hline 5 & Broiler farm & 6 & 45 & 22 & 96 & 62 & 124 & 97 & 446 \\
\hline \multirow[t]{2}{*}{6} & TVCC & 6 & 16 & 74 & 48 & 62 & 55 & 71 & 326 \\
\hline & Total & & & & & & & & 2187 \\
\hline 7 & Fecal swabs (2/visit) & & & & & & & & 72 \\
\hline
\end{tabular}

\section{MATERIALS AND METHODS}

\section{Sampling of flies}

Flies were trapped from livestock (cattle, buffalo, sheep, goat, pigs) \& poultry farm premises and Veterinary Clinical Complex (VCC) using manually prepared traditional traps. The unconventional fly-traps were made out of plastic bottles. Dried fish and chicken powder, in the ratio of 2:1, mixed with sugar syrup was used as bait. Sampling frequency for collection of flies was predetermined so as to collect pooled samples from farm premises. Traps were fixed at different places in the livestock/ poultry sheds where flies were abundant. For each food animal species, trapping was attempted six times, i.e. six pools of samples per species were collected (Table 1). Using no specific selection criteria, $40 \%$ of each catch was processed, provided that the numbers of flies caught are not $\leq 15$, in such case, all the flies were processed for bacterial isolation.

\section{Bacterial culture}

Flies were first washed with 1x Phosphate Buffer Saline (PBS) to remove exterior debris and genus identification was done on the basis of wing pattern under 10x microscopic view (Sen and Fletcher, 1962). Identification at genus and species level was done by expert parasitologist. Identified flies were pooled and washing was carried out three times with $1 \times$ PBS to reduce surface contaminants. Washed pool samples were placed in a fresh tube and centrifuged for $10 \mathrm{~min}$ at $12000 \mathrm{rpm}$. Flies settled at the bottom of the centrifuge tubes were crushed by a sterile metal rod, and mixed with sterile PBS, again centrifuged for $10 \mathrm{~min}$ at 
$6000 \mathrm{rpm}$. The supernatant was collected and used for isolation of E. coli and Salmonella species. Fecal samples randomly collected from cattle, buffalo, sheep, goat, pigs and poultry using rectal/cloacae swabs were also processed for bacterial isolation.

Isolation and identification of $\boldsymbol{E}$. coli and Salmonella species

For obtaining pure culture of E. coli and Salmonella, enrichment followed by selective plating on specific medium was performed. For E. coli, $1 \mathrm{ml}$ supernatant was inoculated into $5 \mathrm{ml}$ Enterobacteriaceae Enrichment Broth (EEB) with incubation at $37{ }^{\circ} \mathrm{C}$ for $24 \mathrm{~h}$. Similarly, rectal/ cloacae swabs were also enriched in $10 \mathrm{ml}$ of EEB for $24 \mathrm{~h}$ at $37{ }^{\circ} \mathrm{C}$. A loop full of enriched culture was streaked on Eosin Methylene Blue (EMB) agar and plates were again incubated at $37{ }^{\circ} \mathrm{C}$ for $24 \mathrm{~h}$. For isolation of Salmonella, pre-enrichment in Buffered Peptone Water (BPW), enrichment in EEB and selective plating on Xylose Lysine Deoxycholate (XLD) agar was done. Fecal swabs and $1 \mathrm{ml}$ supernatant of pooled flies were first inoculated in $9 \mathrm{ml} \mathrm{BPW}$ and incubated at $37^{\circ} \mathrm{C}$ for $24 \mathrm{~h}$. Then, $1 \mathrm{ml}$ of pre-enriched culture was inoculated with $5 \mathrm{ml}$ EEB and incubated overnight at $37^{\circ} \mathrm{C}$. A loop full of the enriched culture was used for selective plating on the XLD agar plates incubated at $37{ }^{\circ} \mathrm{C}$ for $24 \mathrm{~h}$. Three to five representative E. coli and Salmonella colonies were picked up, purified and confirmed by biochemical tests namely, catalase, oxidase, indole, methyl red, Voges Proskaur, $\mathrm{H}_{2} \mathrm{~S}$ production and citrate utilization.

\section{MALDI -TOF MS identification}

Matrix-assisted laser desorption ionization time - of flight (MALDI - TOF) mass spectrometry (MS) technique was used for confirmation of E. coli and Salmonella. Facilities available at Centre for Zoonoses, Department of Veterinary Public Health, Nagpur Veterinary College, MAFSU Nagpur were used for MALDI - TOF MS identification. Isolates were first grown on BHI agar and single colony from BHI agar plate was picked using sterile loop and placed in target plate. Colonies were dissolved in one to two micro liter of matrix solution. Matrix solution was composed of alpha-cyano-4-hydroxycinnamic acid saturated in 50\% acetonitrile and $2.5 \%$ trifluoracetic acid. Target plates were allowed to dry at room temperature and placed into the plate chamber of the mass spectrometer. For calibration of the instrument known standard culture of $E$. coli was used during the assay. The further analysis of the spectra giving clear identification of the organisms was documented (Fig. 1, 2).

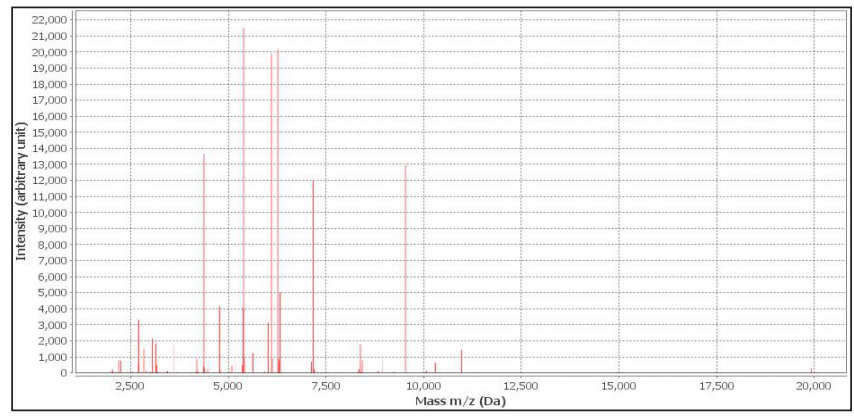

Fig. 1: MALDI-TOF MS spectra of Escherichia coli isolates

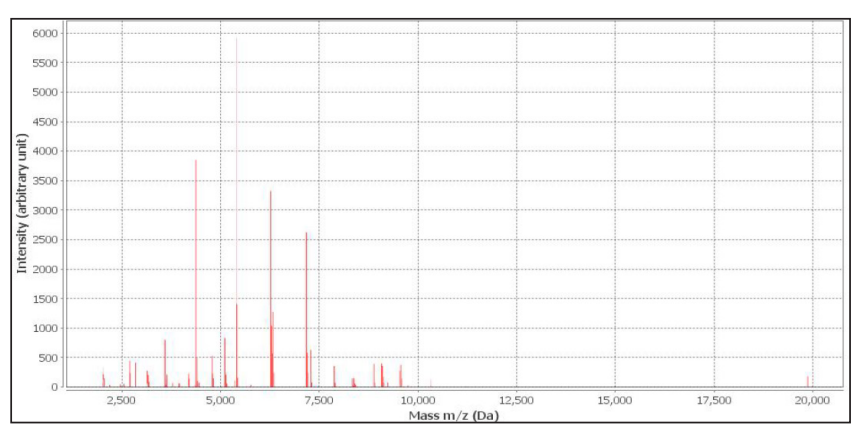

Fig. 2: MALDI-TOFMS spectra of Salmonella enterica subspecies enterica isolates

\section{Antimicrobial susceptibility testing}

Antimicrobial susceptibility and resistance patterns of E. coli and Salmonella species isolated from flies and fecal samples were studied using Kirby-Bauer disc diffusion method and interpreted using criteria suggested by the Clinical and Laboratory Standards Institute (CLSI, 2017). AMR studies were performed using 12 different antimicrobials as depicted in Table 3. Overnight grown bacterial cultures in BHI broth were smeared on Mueller Hinton agar (MHA) plates and antimicrobial discs were placed at suitable distance. After drying, plates were incubated at $37{ }^{\circ} \mathrm{C}$ for $24 \mathrm{~h}$. Zones of inhibition were measured and interpreted in accordance to the manufacturer's instructions (HiMedia Laboratories, Mumbai). 
Wadaskar et al.

Table 2: Oligonucleotide sequences used for multiplex PCR

\begin{tabular}{lll}
\hline Primer name & Sequence (5'-3') & Amplicon size (bp) \\
\hline$m c r-1(\mathrm{~F})$ & AGTCCGTTTGTTCTTGTGGC & 320 \\
$m c r-1(\mathrm{R})$ & AGATCCTTGGTCTCGGCTTG & 715 \\
$m c r-2(\mathrm{~F})$ & CAAGTGTGTTGGTCGCAGTT & \\
$m c r-2(\mathrm{R})$ & TCTAGCCCGACAAGCATACC & 929 \\
$m c r-3(\mathrm{~F})$ & AAATAAAAATTGTTCCGCTTATG & \\
$m c r-3(\mathrm{R})$ & AATGGAGATCCCCGTTTTT & 1116 \\
$m c r-4(\mathrm{~F})$ & TCACTTTCATCACTGCGTTG & \\
$m c r-4(\mathrm{R})$ & TTGGTCCATGACTACCAATG & 1644 \\
$m c r-5(\mathrm{~F})$ & ATGCGGTTGTCTGCATTTATC & \\
$m c r-5(\mathrm{R})$ & TCATTGTGGTTGTCCTTTTCTG & \\
\hline
\end{tabular}

\section{Detection of ESBL production}

Multidrug resistant strains were studied for ESBL production using double disk synergy test (DDST). The procedure involved initial screening followed ESBL confirmation. Cefotaxime $(30 \mu \mathrm{g})$ and ceftazidime (30 $\mu \mathrm{g})$ discs were used for initial screening, and cefotaxime/ clavulanic acid $(30 / 10 \mu \mathrm{g})$ and ceftazidime/clavulanic acid $(30 / 10 \mu \mathrm{g})$ discs for ESBL confirmation. BHI inoculated overnight grown cultures of E. coli and Salmonella were streaked on the MHA plates. Plates were incubated at 37 ${ }^{\circ} \mathrm{C}$ for $24 \mathrm{~h}$ and difference in the zone of inhibition was recorded. Isolates showing difference in zone of inhibition of $\geq 5 \mathrm{~mm}$ of cephalosporin discs and cephalosporin plus clavulanic acid containing disc were considered as potential ESBL producers.

\section{Detection of KPC (Carbapenemase) production}

The isolates showing resistance to carbapenem discs (ertapenem, doripenem, meropenem and imipenem) during initial phenotypic screening were suspected as carbapenemase (KPC) positive. MIC was estimated using ertapenem/ertapenem plus boronic acid Ezy MIC strips (HiMedia). Ten randomly selected KPC positive isolates were cultured overnight in BHI broth and smeared on the MHA plates. The Ezy MIC strips were placed on the MHA plate carefully and incubated at $37^{\circ} \mathrm{C}$ for $24 \mathrm{~h}$. The ratio of ertapenem/ ertapenem + boronic acid $(\mathrm{ETP} / \mathrm{ETP}+)$ more than 8 was considered positive for KPC.
MIC of AmpC (Ampicillin and Carbenicillin) producing isolates

Improved AmpC detection Ezy MIC strips (HiMedia) were used and all the isolates that were commonly resistant to amoxicillin-clavulanic acid, aztreonam and piperacillintazobactum were screened. The Ezy MIC strips containing MIX+ (ceftazidime, cefotaxime, cloxacillin \& clavulanic acid- 0.032 - 4) and MIX (ceftazidime, cefotaxime \& cloxacillin- 0.125 - 16) were placed on MHA plate and incubated at $37^{\circ} \mathrm{C}$ for $24 \mathrm{~h}$. If the ratio of the value of MIX and MIX in combination with clavulanic acid (MIX+) found more than 8 or no zone for MIX and zone obtained in $\mathrm{MIX}+$, it was considered as $\mathrm{ESBL}+\mathrm{AmpC}$ positive strain. When ratio of the value obtained for MIX and MIX+ was $\leq 8$, it was considered as AmpC positive (AmpC present, but ESBL absent).

\section{MIC of MBL (Metallo- $\beta$ Lactamase) producing isolates}

For the determination of MIC of suspected MBL (Metallo$\beta$ Lactamase) producing isolates, the common isolates showing ESBL and AmpC production were selected. Isolates were cultured in $\mathrm{BHI}$ broth and streaked on MHA plates as described above. The MBL plus ESBL Detection Ezy MICTM strips containing ESBL+ (ceftazidime, cefotaxime, EDTA \& clavulanic acid- 0.032 - 4) and ESBL (ceftazidime, cefotaxime \& EDTA- 0.125 - 16) were placed on the agar plate and incubated. When the ratio of the value obtained for ESBL and ESBL+ found more than 8 or no zone obtained for ESBL and zone obtained for $\mathrm{ESBL}+$, it was considered as MBL+ESBL positive strain. 
When the ratio of the value obtained for ESBL and ESBL+ was $\leq 8$, it was considered as MBL positive strain (ESBL is not present along with MBL).

\section{MIC of colistin resistant isolates}

Isolates resistant to $\mathrm{ESBL}, \mathrm{KPC}, \mathrm{MBL}$ and colistin were further screened for estimation of MIC for colistin using Ezy MIC strips (HiMedia). Thirty isolates were cultured in BHI broth and smeared on the MHA plates. The Ezy MIC strips were placed on MHA agar plates and incubated as described previously. Zone inhibition reading at the value of $\geq 2 \mu \mathrm{g} / \mathrm{ml}$ was considered as resistant, and a lesser value was termed as susceptible.

\section{Detection of mobile colistin resistance ( $\mathrm{mcr}$ ) genes}

Phenotypically confirmed colistin resistant isolates of E. coli and Salmonella were screened by multiplex PCR targeting mobile colistin resistance genes viz. morl to $m c r 5$ as per the method described previously (Rebelo et al., 2018). Briefly, bacterial DNA was extracted by boiling and snap chilling method and $2 \mu \mathrm{l}$ of supernatant was used as the DNA template for PCR. Multiplex PCR was performed in $25 \mu \mathrm{l}$ volume containing $12.5 \mu \mathrm{l} 2 \mathrm{x}$ PCR master mix (HiMedia), $0.5 \mu \mathrm{l}$ of each forward and reverse primers $(m c r 1-m c r 5), 2 \mu$ DNA template and $5.5 \mu \mathrm{l}$ nuclease free water to make final volume of $25 \mu \mathrm{l}$. Cycling conditions were set as: initial denaturation (94 ${ }^{\circ} \mathrm{C} / 15 \mathrm{~min}^{-1}$ cycle) followed by 35 cycles of denaturation (94 $\left.{ }^{\circ} \mathrm{C} / 30 \mathrm{sec}\right)$, annealing $\left(58^{\circ} \mathrm{C} / 90 \mathrm{sec}\right)$, and extension $\left(72{ }^{\circ} \mathrm{C} / 60 \mathrm{sec}\right.$ ). Final extension was attained at $72{ }^{\circ} \mathrm{C} / 10$ min and holding at $4{ }^{\circ} \mathrm{C}$. Five microliter amplified product was separated by electrophoresis in $1.5 \%$ agarose gel dissolved in $0.5 \times$ TBE stained by ethidium bromide. Oligonucleotide sequences used are depicted in Table 2.

\section{RESULTS AND DISCUSSION}

\section{Prevalence}

Out of 2187 flies trapped, all were identified as house fly (Musca domestica) and only one blow fly (Calliphora erythrocephala) could be trapped at VCC of the institute. $E$. coli was isolated from all the flies and fecal samples $(100 \%)$. However, isolation rate of Salmonella species was

Journal of Animal Research: v. 11, n. 3, June 2021 comparatively less. It could be isolated from 21 (58.33\%) out of 36 pools of flies and $15(20.83 \%)$ fecal samples. Thus, total 109 E. coli and 36 Salmonellae species were confirmed. Similarly, 35 randomly selected isolates (15 E. coli and 20 Salmonellae) were also confirmed by MALDITOF MS identification system. All the 35 isolates were confirmed as E. coli and Salmonella enterica by MALDI -TOF MS system. Livestock, poultry farm and rural environment provides ideal environment for breeding and propagation of house flies and therefore Muscidae must be the most abundant species near human and animal dwellings. Abundance of house flies and blow flies in the animal farms were previously reported from Thailand (Fukuda et al., 2018). E. coli, Salmonella, Shigella and helminth eggs were recently identified in Musca domestica collected from cattle byres, poultry farms and human houses (Issa, 2019). Musca domestica exposed to the chickens challenged with Salmonella Enteritidis get colonized with strain within $24-48 \mathrm{~h}$ and were able to transmit Salmonellae to naive chicken population (Holt et al., 2007). Foodborne pathogens including bacteria, gastrointestinal parasites and viruses have been isolated from exterior body surface and gut of filth flies collected from human houses, livestock and poultry farms (Hald et al., 2004; Lindeberg et al., 2018). A study from Tamil $\mathrm{Nadu}$, have established link between fly densities and diarrheal episodes in rural and urban households and 99.9\% flies were from Muscidae family. Rotavirus, Salmonella, Shigella and E. coli were isolated from them (Collinet-Adler et al., 2015).

\section{AMR pattern}

All the 145 isolates (109 E. coli and 36 Salmonella) were examined for antimicrobial resistance pattern by disc diffusion method (Table 3). Almost all the E. coli isolates expressed resistance to multiple antibiotics. Most of the $E$. coli strains irrespective of species/source of isolation has shown resistance to amoxicillin-clavulanic acid (100\%), cefotaxime $(93.57 \%)$, aztreonam $(59.63 \%)$, cefpodoxime $(58.71 \%)$ and imipenem (48.62\%). Overall colistin resistance was recorded very low $(12.84 \%)$ and only 14 isolates expressed resistance to colistin by disc diffusion method. Species/source wise prevalence of colistin resistance was recorded as: cattle-buffalo (66.6\%), sheep $(5.5 \%)$, goat $(22.77 \%)$, poultry $(11.11 \%)$, pigs $(11.1 \%)$ and VCC isolates $(5.26 \%)$. E. coli isolates were multi- 
Table 3: Antibiogram of E. coli and Salmonella species ( $\mathrm{n}=145)$

\begin{tabular}{|c|c|c|c|c|c|c|}
\hline \multirow{2}{*}{ Antimicrobials used } & \multicolumn{3}{|c|}{ E. $\operatorname{coli}(\mathrm{n}=109)$} & \multicolumn{3}{|c|}{ Salmonella $(\mathrm{n}=36)$} \\
\hline & Sensitive & Intermediate & Resistant & Sensitive & Intermediate & Resistant \\
\hline $\begin{array}{l}\text { Amoxicillin Clavulanic acid } \\
(20 / 10 \mathrm{mcg})\end{array}$ & $0(0 \%)$ & $0(0 \%)$ & $109(100 \%)$ & $0(0 \%)$ & $0(0 \%)$ & $36(100 \%)$ \\
\hline Aztreonam (30 mcg) & $26(23.8 \%)$ & $18(16.51 \%)$ & $65(59.6 \%)$ & $5(13.8 \%)$ & $11(30.5 \%)$ & $20(55.5 \%)$ \\
\hline Cefotaxime (30 mcg) & $1(0.91 \%)$ & $6(5.50 \%)$ & $102(93.57 \%)$ & $1(2.77 \%)$ & $2(5.55 \%)$ & $33(91.6 \%)$ \\
\hline Cefpodoxime $(10 \mathrm{mcg})$ & $32(29.35 \%)$ & $13(11.9 \%)$ & $64(58.7 \%)$ & $0(0 \%)$ & $2(5.55 \%)$ & $34(94.44 \%)$ \\
\hline Ceftazidime (30 mcg) & $45(41.28 \%)$ & $29(26.6 \%)$ & $35(32.1 \%)$ & $5(13.88 \%)$ & $14(38.8 \%)$ & $17(47.22 \%)$ \\
\hline Ceftriaxone (30 mcg) & $51(46.78 \%)$ & $26(23.85 \%)$ & $32(29.35 \%)$ & $14(38.8 \%)$ & $10(27.7 \%)$ & $12(33.3 \%)$ \\
\hline Colistin (10 mcg) & $84(77.06 \%)$ & $11(10.09 \%)$ & $14(12.8 \%)$ & $11(30.55 \%)$ & $3(8.33 \%)$ & $22(61.11 \%)$ \\
\hline Doripenem (10 mcg) & $36(33.02 \%)$ & $49(44.9 \%)$ & $24(22.01 \%)$ & $21(58.3 \%)$ & $11(30.5 \%)$ & $4(11.11 \%)$ \\
\hline Ertapenem (10 mcg) & $60(55.04 \%)$ & $37(33.94 \%)$ & $12(11 \%)$ & $29(80.55 \%)$ & $6(16.66 \%)$ & $1(2.77 \%)$ \\
\hline Imipenem (10 mcg) & $13(11.9 \%)$ & $43(39.4 \%)$ & $53(48.62 \%)$ & $0(0 \%)$ & $3(8.33 \%)$ & $33(91.66 \%)$ \\
\hline Meropenem (10 mcg) & $22(20 \%)$ & $40(36.69 \%)$ & $47(43.11 \%)$ & $25(69.44 \%)$ & $10(27.7 \%)$ & $1(2.77 \%)$ \\
\hline $\begin{array}{l}\text { Piperacillin- Tazobactam } \\
(100 / 10 \mathrm{mcg})\end{array}$ & $17(15.59 \%)$ & $43(89.4 \%)$ & $47(43.11 \%)$ & $7(19.44 \%)$ & $10(27.7 \%)$ & $19(52.7 \%)$ \\
\hline
\end{tabular}

Table 4: Resistance pattern of $E$. coli isolated from flies and food animals $(\mathrm{n}=109)$

\begin{tabular}{|c|c|c|c|c|c|c|c|c|c|c|c|c|c|c|c|}
\hline \multicolumn{2}{|c|}{ Farm premise and species } & \multicolumn{2}{|c|}{$\begin{array}{l}\text { Cattle/buffalo } \\
\text { (18) }\end{array}$} & \multicolumn{2}{|r|}{$\begin{array}{c}\text { Sheep } \\
(18)\end{array}$} & \multicolumn{2}{|c|}{$\begin{array}{c}\text { Goat } \\
(18)\end{array}$} & \multicolumn{2}{|c|}{$\begin{array}{c}\text { Poultry } \\
\text { (18) }\end{array}$} & \multicolumn{2}{|c|}{$\begin{array}{l}\text { Pig } \\
(18) \\
\end{array}$} & \multicolumn{2}{|c|}{$\begin{array}{c}\text { TVCC } \\
\text { (19) }\end{array}$} & \multicolumn{2}{|c|}{$\begin{array}{l}\text { Overall } \\
\text { resistance }\end{array}$} \\
\hline Antimicrobial & $\mathrm{mcg} / \mathrm{disc}$ & No & $\%$ & No & $\%$ & No & $\%$ & No & $\%$ & No & $\%$ & No & $\%$ & No & $\%$ \\
\hline $\mathrm{AMC}$ & $20 / 10$ & 18 & 100 & 18 & 100 & 18 & 100 & 18 & 100 & 18 & 100 & 19 & 100 & 109 & 100 \\
\hline AT & 30 & 13 & 72.22 & 9 & 50 & 7 & 38.88 & 13 & 72.22 & 10 & 55.55 & 13 & 68.42 & 65 & 59.63 \\
\hline CTX & 30 & 18 & 100 & 17 & 94.44 & 16 & 88.88 & 17 & 94.44 & 17 & 94.44 & 17 & 89.47 & 102 & 93.57 \\
\hline CPD & 10 & 14 & 77.77 & 4 & 22.22 & 11 & 61.11 & 8 & 44.44 & 15 & 83.33 & 12 & 63.15 & 64 & 58.71 \\
\hline $\mathrm{CAZ}$ & 30 & 6 & 33.33 & 3 & 16.66 & 6 & 33.33 & 7 & 38.88 & 6 & 33.33 & 7 & 36.84 & 35 & 32.11 \\
\hline CTR & 30 & 6 & 33.33 & 2 & 11.11 & 6 & 33.33 & 9 & 50 & 4 & 22.22 & 5 & 26.31 & 32 & 29.35 \\
\hline CL & 10 & 3 & 16.66 & 1 & 5.55 & 5 & 22.77 & 2 & 11.11 & 2 & 11.11 & 1 & 5.26 & 14 & 12.84 \\
\hline DOR & 10 & 5 & 22.77 & 4 & 22.22 & 7 & 38.88 & 1 & 5.55 & 4 & 22.22 & 3 & 15.78 & 24 & 22.01 \\
\hline ETR & 10 & 1 & 5.55 & 4 & 22.22 & 3 & 16.66 & 2 & 11.11 & 0 & 0 & 2 & 10.52 & 12 & 11.00 \\
\hline IMP & 10 & 10 & 55.55 & 6 & 33.33 & 11 & 61.11 & 5 & 22.77 & 9 & 50 & 12 & 63.15 & 53 & 48.62 \\
\hline MRP & 10 & 4 & 22.22 & 14 & 77.77 & 8 & 44.44 & 4 & 22.22 & 7 & 38.88 & 10 & 52.63 & 47 & 43.11 \\
\hline PIT & $100 / 10$ & 10 & 55.55 & 5 & 22.77 & 7 & 38.88 & 5 & 22.77 & 12 & 66.66 & 8 & 42.10 & 47 & 43.11 \\
\hline
\end{tabular}

drug resistant strains and out of 109 isolates, 92 isolates (84.40\%) expressed resistance to at least 3 out of 12 antibiotics. Multiple antibiotic resistance (MAR) index for the individual strains vary from 0.25 to 0.75 . AMR pattern of E. coli and Salmonella species isolated from flies and fecal samples of food animals is presented in Table 4 and 5. Overall, Salmonella isolates showed $100 \%$ resistance to Ampicillin-clavulanic acid followed by cefotaxime (91.66\%), cefpodoxime (94.44\%), imipenem (91.66\%), colistin (61.11\%) and piperacillin-tazobactam (52.77\%).
Resistance to ertapenem, meropenem and doripenem was very low. Colistin resistant strains of Salmonella were isolated from flies as well as fecal samples and its prevalence was high $(61.11 \%)$ as compared to colistin resistant E. coli $(12.84 \%)$. Highest number of colistin resistant strains were recovered from pig farm (90\%) and VCC (80\%) premise. Resistance to multiple antimicrobials was also recorded in the Enterobacteriaceae including $E$. coli isolated from flies collected at dairy and poultry sites in Portugal (Barreiro et al., 2013). Detection of AMR 
Table 5: Resistance pattern of Salmonella isolated from flies and food animals ( $\mathrm{n}=36$ )

\begin{tabular}{|c|c|c|c|c|c|c|c|c|c|c|c|c|c|c|c|}
\hline \multicolumn{2}{|c|}{ Farm premise and species } & \multicolumn{2}{|c|}{$\begin{array}{c}\text { Cattle/ } \\
\text { buffalo (5) }\end{array}$} & \multicolumn{2}{|r|}{$\begin{array}{l}\text { Sheep } \\
\text { (7) }\end{array}$} & \multicolumn{2}{|c|}{$\begin{array}{l}\text { Goat } \\
\text { (1) }\end{array}$} & \multicolumn{2}{|c|}{$\begin{array}{c}\text { Poultry } \\
\text { (8) }\end{array}$} & \multicolumn{2}{|c|}{$\begin{array}{l}\text { Pig } \\
\text { (10) }\end{array}$} & \multicolumn{2}{|c|}{$\begin{array}{c}\text { TVCC } \\
(5)\end{array}$} & \multicolumn{2}{|c|}{$\begin{array}{c}\text { Overall } \\
\text { resistance }\end{array}$} \\
\hline Antimicrobial & $\mathrm{mcg} / \mathrm{disc}$ & No & $\%$ & No & $\%$ & No & $\%$ & No & $\%$ & No & $\%$ & No & $\%$ & No & $\%$ \\
\hline $\mathrm{AMC}$ & $20 / 10$ & 5 & 100 & 7 & 100 & 1 & 100 & 8 & 100 & 10 & 100 & 5 & 100 & 36 & 100 \\
\hline AT & 30 & 3 & 60 & 5 & 71.42 & 1 & 100 & 5 & 62.5 & 4 & 40 & 2 & 40 & 20 & 55.55 \\
\hline CTX & 30 & 4 & 80 & 7 & 100 & 1 & 100 & 7 & 87.5 & 9 & 90 & 5 & 100 & 33 & 91.66 \\
\hline CPD & 10 & 5 & 100 & 6 & 85.71 & 1 & 100 & 7 & 87.5 & 10 & 100 & 5 & 100 & 34 & 94.44 \\
\hline $\mathrm{CAZ}$ & 30 & 1 & 20 & 3 & 42.85 & 0 & 0 & 4 & 50 & 6 & 60 & 3 & 60 & 17 & 47.22 \\
\hline CTR & 30 & 3 & 60 & 2 & 28.57 & 0 & 0 & 0 & 0 & 7 & 70 & 0 & 0 & 12 & 33.33 \\
\hline $\mathrm{CL}$ & 10 & 2 & 40 & 3 & 42.85 & 1 & 100 & 3 & 37.5 & 9 & 90 & 4 & 80 & 22 & 61.11 \\
\hline DOR & 10 & 1 & 20 & 1 & 14.28 & 1 & 100 & 0 & 0 & 1 & 10 & 0 & 0 & 4 & 11.11 \\
\hline ETR & 10 & 1 & 20 & 0 & 0 & 0 & 0 & 0 & 0 & 0 & 0 & 0 & 0 & 1 & 2.77 \\
\hline IMP & 10 & 4 & 80 & 5 & 71.42 & 1 & 100 & 8 & 100 & 10 & 100 & 5 & 100 & 33 & 91.66 \\
\hline MRP & 10 & 0 & 0 & 0 & 0 & 0 & 0 & 0 & 0 & 0 & 0 & 1 & 20 & 1 & 2.77 \\
\hline PIT & $100 / 10$ & 3 & 60 & 4 & 57.14 & 1 & 100 & 3 & 37.5 & 4 & 40 & 4 & 80 & 19 & 52.77 \\
\hline
\end{tabular}

strains of E. coli and Salmonella isolated from flies and fecal samples of farm animals is worrisome as flies can carry antimicrobial resistant microbes mechanically from animals to humans. AMR in E. coli isolated from flies (Sobur et al., 2019) and food animals (Malhotra-Kumar et al., 2016) were studied earlier. In contrast to present findings ertapenem, imipenem and meropenem susceptible E. coli were found in healthy cattle from Spain (Hernández et al., 2017). In another cross sectional study on houseflies collected from educational hospitals, vegetable centre and livestock slaughter house, E. coli resistant to gentamicin, cefotaxine, ciprofloxacin and other routine drugs were detected (Nazari et al., 2017). Salmonella isolates under study showed very high resistance to ampicillinclavulanic acid, cefotaxime, cefpodoxime, imipenem and colistin. However, resistance to ertapenem, meropenem and doripenem was very low. A recent study on AMR diversity of Salmonella Typhimurium exhibited high degree of AMR diversity in pig isolates as compared to chicken and cattle origin isolates (Mellor et al., 2019). Isolation and characterization of E. coli and Salmonella from flies for AMR is not extensively investigated and there are no supporting reports from India with reference to AMR in bacteria associated with flies trapped at livestock and poultry farms. Present findings affirm that Musca domestica flies prevalent at livestock and poultry farms harbor multi-drug resistant strains of E. coli and Salmonella.

\section{ESBL, MBL, AmpC, KPC and Colistin resistance}

Out of 109 E. coli, $23(21.10 \%)$ were ESBL positive strains. Among these, 8 (34.78\%) isolates were from flies and $15(65.21 \%)$ were from fecal samples. The distribution of ESBL positive $E$. coli revealed maximum isolates from broiler (6/23), followed by goat (4/23), sheep (4/23), cattle $(4 / 23)$, pig $(3 / 23)$ and VCC (2/23) origin samples. Similarly, prevalence of ESBL positive Salmonella was $19.44 \%$ and out of 36 , seven strains were ESBL positive. Only one isolate was from fly source and other six strains were from fecal samples. Isolates resistant to amoxicillinclavulanic acid, aztreonam and piperacillin- tazobactam during initial screening, were suspected as AmpC positive strains, however, all the isolates were negative for AmpC by Ezy MIC strips. Similarly, eight common ESBL and amoxicillin-clavulanic acid resistant isolates were screened for MBL type of resistance using Ezy MIC strips. Two isolates were positive for MBL, ESBL and AmpC production, while six were positive for $\mathrm{MBL}$ only. Further, 10 common isolates resistant to doripenem, meropenem, ertapenem and imipenem were screened for KPC using Ezy MIC strips and only one goat fecal origin E. coli was carbapenemase positive. Resistance to ESBLs, AmpC cephalosporinases, and carbapenem antibiotics are of greater public health significance. Thus, detection of ESBL, MBL, AmpC, KPC and colistin resistance in E. coli and Salmonella is highly significant in the recent context. ESBL positive E. coli strain was also detected in two fly 
pools collected from the poultry farms in the Netherlands (Blaak et al., 2014). In contrast to our findings, AmpC producing $E$. coli were highly prevalent in the broiler birds and farmers working at Dutch farms (Dierikx et al., 2013).

Initial phenotypic screening by the disc diffusion method revealed $12.84 \%$ E. coli and $61.11 \%$ Salmonella resistant to colistin. Out of these, 30 isolates (13 E. coli and 17 Salmonella) were examined for MIC of colistin. Overall, $16(53.33 \%)$ isolates found positive for colistin at a MIC level of $\geq 2 \mathrm{mg} / \mathrm{L}$. Of these, 10 were $E$. coli and 6 were Salmonella. Maximum E. coli isolates showing MIC $\geq 2$ $\mathrm{mg} / \mathrm{L}$ were of goat origin (three), followed by cattle and pig (one each). Colistin positive $E$. coli with $\mathrm{MIC} \geq 2 \mathrm{mg} / \mathrm{L}$ could be isolated from two fly pools trapped at poultry farm and one each from cattle farm, goat farm and VCC. Out of six positive Salmonella isolates showing MIC of $\geq$ $2 \mathrm{mg} / \mathrm{L}$, two each, were from flies collected at sheep farm, pig farm and VCC (Fig. 3, 4, 5).
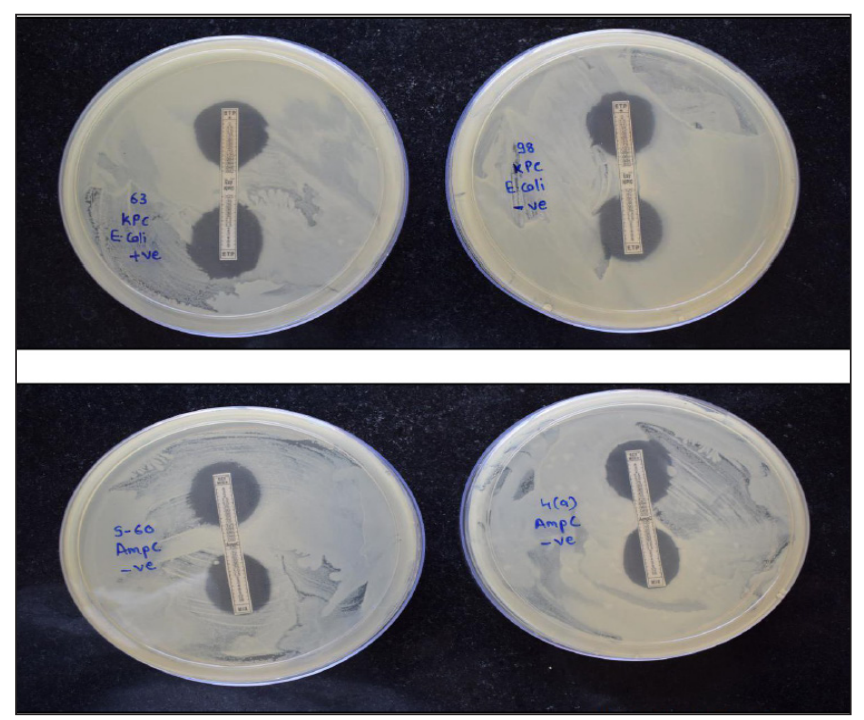

Fig. 3: Detection of carbapenemase and AmpC producing isolates using Ezy MIC strips

Multiplex PCR was performed on all the 34 colistin positive isolates as per the standard protocol, however, we could not detected $\mathrm{mcr}$ genes in any of the phenotypically colistin resistant E. coli and Salmonella isolates. Use of colistin (polymyxin E) has been re-introduces in human medicine and now it is a last resort antibiotic to treat infections from multi-drug resistant bacteria. As compared to our study, less prevalence of colistin resistant E. coli isolated from livestock and food was noted in Germany (Irrgang et al., 2016).

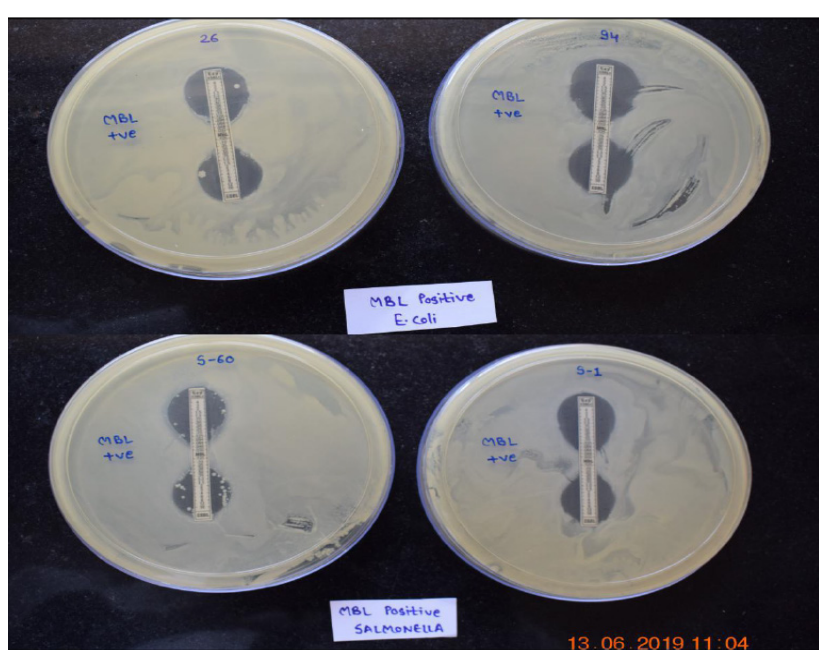

Fig. 4: Detection of MBL production using Ezy MIC strips

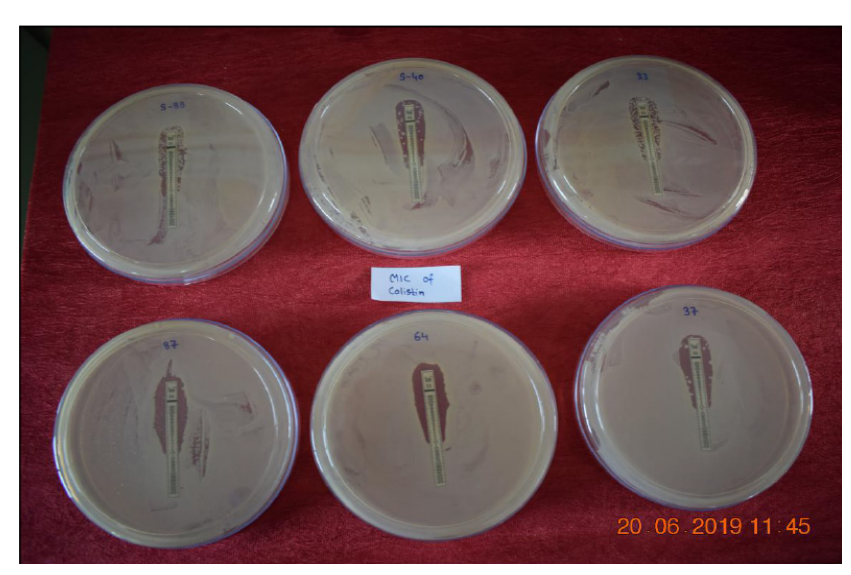

Fig. 5: Detection of colistin resistance using Ezy MIC strips

Similar to the present observations high frequency of colistin resistance in pigs $(23.75 \%)$ and poultry $(7.92 \%)$ was recorded in a study from China (Huang et al., 2017). Sporadic reports are available on detection of $\mathrm{mcrl}$ and $m c r 3$ genes in E. coli isolated from flies (Fukuda et al., 2018; Sobur et al., 2019). Other than India, prevalence of mor genes in E. coli and Salmonella isolated from food animals has been reported globally (El Garch et al., 2018). As colistin is used as last resort antibiotic, development of resistance against this important antibiotic is great cause of concern. 


\section{CONCLUSION}

Present findings highlighted the significance of flies in harboring multi-drug resistant E. coli and Salmonella species. Although, colistin resistance could not be confirmed by PCR during this study, detection of ESBL, MBL, and colistin resistance by phenotypic assays warrants the need for undertaking extensive monitoring of AMR in bacterial pathogens present in the invertebrate species associated with animal and human dwellings. It is assumed that variety of invertebrate species living in close proximity to animals may be a source of gene pool for antimicrobial resistance and their role in AMR transmission from animals to humans cannot be ruled out.

\section{ACKNOWLEDGMENTS}

Authors are thankful to the Associate Dean KNP College of Veterinary Science, Shirwal for financial support and In-Charge CIF, KNPCVS Shirwal and ICAR NAE, "Centre for zoonosis" Department of VPH, NVC Nagpur for providing laboratory facilities for this research.

\section{REFERENCES}

Barreiro, C., Albano, H., Silva, J. and Teixeira, P. 2013. Role of flies as vectors of foodborne pathogens in rural areas. ISRN Microbiol., 7: 718780.

Blaak, H., Hamidjaja, R.A., van Hoek, A.H., de Heer, L., de Roda Husman, A.M. and Schets, F.M. 2014. Detection of extended-spectrum beta-lactamase (ESBL)-producing Escherichia coli on flies at poultry farms. Appl. Environ. Microbiol., 80(1): 239-246.

Clemente, L., Manageiro, V., Correia, I., Amaro, A., Albuquerque, T., Themudo, P., Ferreira, E. and Caniça, M. 2019. Revealing mcr-1-positive ESBL-producing Escherichia coli strains among Enterobacteriaceae from food-producing animals (bovine, swine and poultry) and meat (bovine and swine), Portugal, 2010-2015. Int. J. Food. Microbiol., 296: 37-42.

Clinical Laboratory Standard Institute (CLSI). 2017. Performance standards for antimicrobial susceptibility testing. $27^{\text {th }} \mathrm{Ed}$., CLSI supplement M100 Clinical and Laboratory Standards Institute, Wayne, PA.

Collinet-Adler, S., Babji, S., Francis, M., Kattula, D., Premkumar, P. S., Sarkar, R., Mohan, V.R., Ward, H., Kang, G., Balraj, V. and Naumova, E.N. 2015. Environmental factors associated with high fly densities and diarrhea in Vellore, India. Appl. Environ. Microbiol., 81(17): 6053-6058.
Dierikx, C., van der Goot, J., Fabri, T., van Essen-Zandbergen, A., Smith, H. and Mevius, D. 2013. Extended-spectrum- $\beta-$ lactamase- and AmpC- $\beta$-lactamase-producing Escherichia coli in Dutch broilers and broiler farmers. J. Antimicrob. Chemother., 68(1): 60-67.

El Garch, F., de Jong, A., Bertrand, X., Hocquet, D. and Sauget, M. 2018. mcr-1-like detection in commensal Escherichia coli and Salmonella spp. from food-producing animals at slaughter in Europe. Vet. Microbiol., 213: 42-46.

Fukuda, A., Usui, M., Okubo, T., Tagaki, C., Sukpanyatham, N. and Tamura Y. 2018. Co-harboring of cephalosporin (bla)/ colistin $(\mathrm{mcr})$ resistance genes among Enterobacteriaceae from flies in Thailand. FEMS Microbiol. Lett., 365(16): fny 178 .

Hald, B., Skovgård, H., Bang, D.D., Pedersen, K., Dybdahl, J., Jespersen, J.B. and Madsen, M. 2004. Flies and Campylobacter infection of broiler flocks. Emerg. Infect. Dis., 10(8): 1490-1492.

Hernández, M., Iglesias, M.R., Rodríguez-Lázaro, D., Gallardo, A., Quijada, N., Miguela-Villoldo, P., Campos, M.J., Píriz, S., López-Orozco, G., de Frutos, C., Sáez, J. L., Ugarte-Ruiz, M., Domínguez, L. and Quesada, A. 2017. Co-occurrence of colistin-resistance genes mcr- 1 and $m c r-3$ among multidrugresistant Escherichia coli isolated from cattle, Spain, September 2015. Euro Surveillance., 22(31): 30586.

Holt, P.S., Geden, C.J., Moore, R.W. and Gast, R.K. 2007. Isolation of Salmonella enterica serovar Enteritidis from houseflies (Musca domestica) found in rooms containing Salmonella serovar Enteritidis-challenged hens. Appl. Environ. Microbiol., B 19): 6030-6035.

Huang, X., Yu, L., Chen, X., Zhi, C., Yao, X., Liu, Y., Wu, S., Guo, Z., Yi, L., Zeng, Z. and Liu, J. H. 2017. High Prevalence of Colistin Resistance and mcr-1 Gene in Escherichia coli Isolated from Food Animals in China. Front. Microbiol., 8: 562.

Irrgang, A., Roschanski, N., Tenhagen, B.A., Grobbel, M., Skladnikiewicz-Ziemer, T., Thomas, K., Roesler, U. and Käsbohrer, A. 2016. Prevalence of mcr-1 in E. coli from livestock and food in Germany, 2010-2015. PloS One, 11(7): e0159863.

Issa, R. 2019. Musca domestica acts as transport vector hosts. Bull. Nat. Res. Centre., 43: 73.

Junqueira, A., Ratan, A., Acerbi, E., Drautz-Moses, D.I., Premkrishnan, B., Costea, P.I., Linz, B., Purbojati, R. W., Paulo, D.F., Gaultier, N.E., Subramanian, P., Hasan, N.A., Colwell, R.R., Bork, P., Azeredo-Espin, A., Bryant, D.A. and Schuster, S.C. 2017. The microbiomes of blowflies and houseflies as bacterial transmission reservoirs. Sci. Rep., 7(1): 16324. 
Lindeberg, Y.L., Egedal, K., Hossain, Z.Z., Phelps, M., Tulsiani, S., Farhana, I., Begum, A. and Jensen, P.K.M. 2018. Can Escherichia coli fly? The role of flies as transmitters of $E$. coli to food in an urban slum in Bangladesh. Trop. Med. Int. Health, 23(1): 2-9.

Malhotra-Kumar, S., Xavier, B.B., Das, A.J., Lammens, C., Hoang, H.T., Pham, N.T. and Goossens, H. 2016. Colistinresistant Escherichia coli harbouring $\mathrm{mcr}-1$ isolated from food animals in Hanoi, Vietnam. Lancet Infect. Dis., 16(3): 286-297.

Marshall, B.M. and Levy, S.B. 2011. Food animals and antimicrobials: impacts on human health. Clin. Microbiol. Rev., 24(4): 718-733.

Mellor, K.C., Petrovska, L., Thomson, N.R., Harris, K., Reid, S. and Mather, A.E. 2019. Antimicrobial Resistance Diversity Suggestive of Distinct Salmonella Typhimurium Sources or Selective Pressures in Food-Production Animals. Front. Microbiol., 10: 708.

Nazari, M., Mehrabi, T., Hosseini, S. M., and Alikhani, M. Y. 2017. Bacterial contamination of adult house flies (Musca domestica) and sensitivity of these bacteria to various antibiotics, captured from Hamadan city, Iran. J. Clin. Diagn. Res., 11 (4): DC04-DC07.

Onwugamba, F.C., Fitzgerald, J.R., Rochon, K., Guardabassi, L., Alabi, A., Kühne, S., Grobusch, M.P. and Schaumburg, F. 2018. The role of 'filth flies' in the spread of antimicrobial resistance. Travel. Med. Infect. Dis., 22: 8-17.

Principe, L., Piazza, A., Mauri, C., Anesi, A., Bracco, S., Brigante, G., Casari, E., Agrappi, C., Caltagirone, M., Novazzi, F., Migliavacca, R., Pagani, L. and Luzzaro, F. 2018. Multicenter prospective study on the prevalence of colistin resistance in Escherichia coli: relevance of $\mathrm{mcr}$-1positive clinical isolates in Lombardy, Northern Italy. Infect. Drug Resist., 11: 377-385.
Rebelo, A.R., Bortolaia, V., Kjeldgaard, J.S., Pedersen, S.K., Leekitcharoenphon, P., Hansen, I.M., Guerra, B., Malorny, B., Borowiak, M., Hammerl, J.A., Battisti, A., Franco, A., Alba, P., Perrin-Guyomard, A., Granier, S. A., De Frutos Escobar, C., Malhotra-Kumar, S., Villa, L., Carattoli, A. and Hendriksen, R.S. 2018. Multiplex PCR for detection of plasmid-mediated colistin resistance determinants, $\mathrm{mcr}-1, \mathrm{mcr}-2, \mathrm{mcr}-3, \mathrm{mcr}$ 4 and $m c r-5$ for surveillance purposes. Euro Surveillance., 23(6): 17-00672.

Sen, S.K. and Fletcher, T.B. 1962. Veterinary Entomology and Acarology for India. $1^{\text {st }}$ Ed., Indian council of Agricultural Research, New Delhi.

Singh, S., Pathak, A., Kumar, A., Rahman, M., Singh, A., Gonzalez-Zorn, B. and Prasad, K.N. 2018. Emergence of chromosome-borne colistin resistance gene $\mathrm{mcr}-1$ in clinical isolates of Klebsiella pneumoniae from India. Antimicrob. Agents Chemother., 62(2): e01885-17.

Sobur, M.A., Ievy, S., Haque, Z.F., Nahar, A., Zaman, S.B. and Rahman, M.T. 2019. Emergence of colistinresistant Escherichia coli in poultry, house flies, and pond water in Mymensingh, Bangladesh. J. Adv. Vet. Anim. Res., 6(1): $50-53$.

Wang, C., Feng, Y., Liu, L., Wei, L., Kang, M. and Zong, Z. 2020. Identification of novel mobile colistin resistance gene mcr-10. Emerg. Microbes. Infect., 9(1): 508-516.

Zhang, J., Wang, J., Chen, L., Yassin, A.K., Kelly, P., Butaye, P., Li, J., Gong, J., Cattley, R., Qi, K. and Wang, C. 2017. Housefly (Musca domestica) and Blow Fly (Protophormia terraenovae) as vectors of bacteria carrying colistin resistance genes. Appl. Environ. Microbiol., 84(1): e01736-17. 